\title{
Monitoring and Evaluation Model of Academic Lecturer Performance in Otorhinolaryngology and Head Neck Surgery's Specialist Medical Education Program
}

\author{
Muyassaroh $^{1}$ Samsudi $^{2}$ Suwito Eko Pramono ${ }^{3}$ Endang Kustiowati ${ }^{4}$ \\ $\left\{\right.$ muyastht@gmail.com $\left.{ }^{1}\right\}$ \\ Education Management Department, Postgraduate program Universitas Negeri Semarang, Indonesia ${ }^{1}$ \\ Kariadi Hospital, Semarang, Indonesia ${ }^{4}$
}

\begin{abstract}
The performance of clinical teaching physicians is measured based on workload covering the main activities namely service, education, research, community service, in accordance with the vision and mission of the institution. The academic performance in quantity has largely met the standards, but if it is related to the outcomes of graduate students on time is less than the standard, so it is necessary to improve the quality of education services. It is necessary to increase monitoring and evaluation of academic performance of permanent and clinical lecturers. This study aims to analyze and monitor system and evaluation of academic performance of clinical lecturers in Otorhinolaryngology and head neck surgery's (ORL-HNS) specialist medical education program. This study applied a qualitative approach using primary and secondary data sources collected through interviews, questionnaires, and documentation. The data is analyzed by interactive analysis methods. Based on the research, it was found that monitoring and evaluation of clinical lecturers of ORL-HNS's specialist medical education program had been carried out, however the monitoring and evaluation process has not been conducted comprehensively and continuously. Monitoring and evaluation are not well prepared and not followed by follow-up. Therefore, the quality of clinical lecturers is not adequately monitored and results in less than optimal academic performance.
\end{abstract}

Keywords: Clinical Lecturer, Academic Performance, Monitoring and Evaluation, ORLHNS's specialist medical education program

\section{Introduction}

The learning process is largely determined by the competence and performance of teaching staff. Teaching educators competency with high commitment will be able to deliver a good quality of learning process. ${ }^{1}$ Lecturers in general and clinical lecturers are one of the crucial factors in the success of educational institutions. In addition to academic ability, lecturer performance is the main entity.,3 Research on the quality of clinical educators is mostly done in the western, whereas in the eastern is still rarely carried out. ${ }^{4}$ Evaluation of the quality of teaching in medical faculties using five criteria: learning climate, effective communication, professional attitudes, evaluation from student, and feedback. ${ }^{5}$ 
In Indonesia, the performance of clinical educator doctors is measured based on workload covering the main activities namely service, education, research, community service, in accordance with the vision and mission of the institution. The regulation sets the standard for the achievement of the performance of clinical educators in the form of credit score assessments consisting of the main elements and supporting elements. 6One of the successes in the field of education is shown by learning achievement and on time graduation from students. The number of lecturers' research products illustrating their role as scientists and community service shows the implementation of the tri dharma of higher education for lecturers.3

Educator and educational staff standards have been met. However, the research activities carried out are still small and the graduation on time has only reached $10 \% .7$ This showed that it is necessary to improve the quality of education of specialist doctors. Efforts to guarantee the quality of education units must be carried out by implementing a quality management or quality assurance system. One of the stages of quality assurance is the monitoring and evaluation of learning including monitoring and evaluation of teacher performance. 2 This study aim to analyze the academic lecturer monitoring and evaluation system performance of clinical lecturers in the otorhinolaryngology and head neck surgery's (ORL-HNS) spesialist medical education program.

\section{Methods}

The study was conducted with a qualitative approach, which was considered effective because this research was directed at a detailed, objective, and clear assessment of the monitoring and evaluation system of academic performance of clinical lecturers. The data source of this study consisted of primary data and secondary data. Primary data include education process data, behavior data or habits of students and lecturers. Secondary data includes data on educational outcomes, regulations, policies, existing assessments, and data obtained from relevant agencies, including government regulations, ministerial regulations, and other policies on higher education, especially those related to specialist medical education.

The subjects in this study were students and clinical educator doctors of ORL-HNS's spesialist medical education program of Medicine Diponegoro University - Kariadi hospital. The selection of subjects is more of a "purposive sampling". Researchers are more likely to choose subjects who are considered to know and can be trusted as sources of data and know the problem in depth.8,9

Data collection in research carried out through questionnaire techniques, interviews, and documentation. Questionnaires were distributed to students to determine students' responses and perceptions regarding the monitoring and evaluation of clinical educator doctors. Interviews were conducted to reveal the problems faced by lecturers, students, and managers therefore the strengths and weaknesses of the existing system can be found. Documentation is done by conducting a study of student data documents, assessment data, policy data, other academic data that support. The analysis technique that can be used to analyze data is interactive model analysis. In the interactive analysis process, there are three main components that must be understood and considered by each researcher, namely : data reduction, data presentation, and drawing conclusions or verification.8,9 


\section{Result and Discussion}

Assessment of the quality of teaching uses four dimensions, namely structure, process, character of educators, and results. The evaluation tools must be guided by the dimensions targeted in the evaluation.10 Monitoring and Evaluation of the academic performance of clinical lecturers ORL-HNS'a spesialist medical education program is done through various stages and methods. Performance appraisals have been carried out so far using methods and techniques issued by the Ministry of Research Technology and Higher Education, the Ministry of Health, and each institution. The monitoring and evaluation guidelines are in the form of a checklist that contains variables of the main task plan, 1 year calculation in the form of employee performance unit. 6

During this time, evidence in the field and documentary data have noted that the monitoring and evaluation of clinical teaching physicians has been carried out. However, if researcher explored further, the fact shows that the process of monitoring and evaluation of clinical educators has not done comprehensively and continuously. Monitoring and evaluation carried out so far are only limited to meeting accreditation demands for the institution. Monitoring and evaluation carried out by internal institutions is only used as a condition in fulfilling the accreditation burden. Monitoring and evaluation are not yet done with careful planning and the results obtained from monitoring and evaluation are not followed by meaningful follow-up.

The doctor's education program had comprehensively evaluated with an integrated approach.11 Previous study using EFFECT-S method showed that evaluation is not only sufficient with instruments but also need comprehensive tests, to improve the quality of lecturer performance.12,13 So far, monitoring and evaluation of clinical educator doctors is rarely done. Monitoring and evaluation is mostly carried out on teaching lecturers who are under the auspices of the Ministry of Research and Technology, whereas clinical teaching doctors who are under the auspices of the Ministry of Health very rarely receive monitoring and evaluation from the institution. This condition shows an imbalance between monitoring and evaluation of lecturers from Ministry of Research, Technology and Higher Education and clinical lecturers from the Ministry of Health. The lack of monitoring and evaluation carried out, causing the institution to not know the quality of academic performance of clinical lecturers so far can not make improvements.

The monitoring and evaluation is also not followed by comprehensive monitoring and evaluation indicators. Of the many monitoring and evaluation indicator points that have been carried out so far, only a few have focused or concerned the quality of the performance of clinical educators.

Evaluation through students is recomemended by emphasizing qualitative methods to get more detailed data. It based on student's opinion regarding the strengths and weaknesses of clinical lecturers in mentoring. This method can be used as reflection material for clinical lecturers to improve their academic performance in the future. 14

Monitoring and evaluation through students is carried out at each change of semester, mid-semester, change of division, and on the eve of accreditation. Usually, monitoring and evaluation through students is done using google forms so that data can be recorded and recap quickly. Monitoring and evaluation with Google Form also allows more students to participate because of the ease in spreading the questionnaire. In addition, the use of Google forms also allows students to give an objective assessment without feeling afraid of their position.

Monitoring and evaluation efforts by students is a strategic step taken by the institution. However, monitoring and evaluation are often only used as administrative requirements in 
semester changes and division changes. Many students fill out the monitoring and evaluation questionnaire only as a form of formality. This causes the assessment in monitoring and evaluation submitted by students to be inaccurate and not in accordance with the conditions on the ground. Then, the results of monitoring and evaluation of students are also not used as material for improvement and reflection for clinical lecturers to improve the quality of their performance.

The lack of monitoring and evaluation of clinical educator doctors has had an influence on the performance of clinical teaching doctors, especially performance in the academic field. This is clearly reflected in the teaching patterns and guidance provided by clinical lecturers to students. So far, the teaching patterns and guidance of the ORL-HNS's medical education program are still not optimal. During this time there is still a gap between teaching and theoretical guidance with teaching and practical guidance (operative guidance). Clinical lecturers have a greater portion of teaching practically compared to theoretically. Practical guidance is mostly done through various activities. Supposedly, clinical lecturers have an obligation to provide teaching theory as well, but only a small portion.

This imbalance in the portion of the guidance causes students to have high professionalism practically but they have low theoretical competence. Students often feel confused in understanding theories related to their scientific fields. Clinical lecturers are often absent from face-to-face lectures in class and only give assignments to students. Students read more theories independently by utilizing a variety of existing literature, for example textbooks, scientific journals, research results, and various other relevant literature. In their independent efforts to learn various theories, often some students experience confusion and differences in perception. Under these conditions, the presence of clinical lecturers is needed to provide guidance and direction to students. However, the contribution of lecturers in this theoretical guidance is still minimal.

In practical guidance there are still several obstacles, including the intensity of guidance provided by clinical lecturers which is still minimal. Clinical lecturers do not have much time to provide guidance to students. This condition causes students only to have a little time to discuss with clinical lecturers. This lack of discussion time causes students to experience confusion when there is a case in practice that turns out to be irrelevant to the theory they have learned. This is also due to the lack of a structured or programmed practical or operational guidance schedule between students and clinical lecturers. Then, clinical lecturers also do not provide much interactive guidance with students.

This condition indicates that there are still obstacles that occur in clinical lecturers in carrying out their performance. This obstacle occurs due to the excessive performance burden borne by the clinical lecturer. Clinical lecturers are not only burdened with demands for academic performance in the form of education and teaching obligations of doctors and specialist doctors. Clinical lecturers must also bear the burden of performance in accordance with the demands of other Higher Education Tri Dharma, namely the field of research and dedication, then coupled with the performance burden as a specialist who must provide specialist services and treatment to patients, as well as the burden of performance in the form of supporting other Doctoral tasks.

The biggest performance assignment that often hinders the academic performance of clinical lecturers is its burden as a specialist doctor who must provide specialist services and treatment to patients. The tight schedule of services and treatment of patients as well as the large number of patients who must be served by clinical lecturers often causes clinical lecturers to be less optimal in providing teaching and guidance to students. Not all clinical lecturers have good time management to handle the entire workload so that clinical lecturers 
spend more time providing specialist services to patients. Therefore, what happens then is the lack of discussion time between clinical lecturers and students and the lack of theories presented by clinical lecturers to their students.

This condition indicates the importance of monitoring and evaluation of Clinical Lecturers in ORL-HNS's spesialist medical education program in a comprehensive, regular and sustainable manner. Lack of continuous monitoring and evaluation results in clinical lecturers not performing their academic performance well. Most clinical lecturers cannot divide their time to carry out their entire workload, including performance in academics. Most clinical lecturers prioritize their performance as doctors, namely specialist services compared to carrying out their performance in the academic field to guide students.

Less optimal performance of clinical lecturers can be detected from how clinical lecturers provide learning resources for their students. Not all clinical lecturers are able to utilize learning resources properly to improve students' competencies. Some clinical lecturers have not been able to combine various learning resources available so they have not been able to provide quality literature. There are still clinical lecturers who have not used up-to-date learning resources in accordance with the times, by combining theoretical and practical learning resources.

However, there are also some clinical lecturers who are able to take learning resources appropriately, namely those that are theoretical by utilizing scientific journals, textbooks, lecture modules, and data from relevant research results. The practical learning resources are obtained by utilizing real cases or phenomena through case studies from patients served by doctors, from the doctor's experience, and the latest health news so that it is real and easily accepted by students. Then, clinical lecturers associate these practical learning resources with theories learned by students. Often the lack of guidance process causes students to experience confusion in understanding the material.

The lack of monitoring and evaluation also causes uninterrupted quality of guidance from clinical lecturers. During this time, clinical lecturers are less able to establish good chemistry with students. Students still often feel the learning atmosphere is monotonous, tense, and full of burden. Then, clinical lecturers are also less able to motivate student in the teaching process. This is due to the pattern of clinical lecturer guidance is less able to establish personal closeness with students as well as the many tasks and responsibilities of clinical lecturers that should be completed by students. In addition, the long waiting time and implementation of operating hours that must be taken by students as assistant physicians in charge of patients so that it will add to the task and time-consuming workmanship.

\section{Conclusion}

Monitoring and evaluation of clinical lecturers of ORL-HNS's spesialist medical education program Faculty of Medicine Diponegoro University-Kariadi hospital has been carried out, but so far the monitoring and evaluation process has not been done comprehensively and continuously. Monitoring and evaluation is only limited to meet the accreditation demands for the institution so that it is not done with careful planning. The results obtained from monitoring and evaluation are not followed by meaningful follow-up efforts. Monitoring and evaluation that has been carried out is not followed by comprehensive monitoring and evaluation indicators. Monitoring and evaluation through students is not optimal because monitoring and evaluation is only used as an administrative requirement 


\section{References}

[1] Fendrik M, Zariul A. Education policy sd towards a new paradigm through the professionalism of teacher. J Basicedu. 2018;1:22-32

[2] Ridwan.AS, SoegitoAT, Rif'an M, Triatna C. Sistem penjaminan mutu internal (seri Penjaminan Mutu Pendidikan). Tangerang: Tira Smart. 2018.

[3] Soegito AT. Total quality management (TQM) in University. Semarang: Unnes Press. 2011.

[4] Kikukawa M, Stalmeijer RE, Emura S, Roff S, Scherpbier A. An instrument for evaluating clinical teaching in Japan: content validity and cultural sensitivity. BMC Med Educ. 2014;14:179

[5] Arah OA, Hoekstra JBL, Bos AP, Lombarts KMJMH. New tools for systematic evaluation of teaching qualities of medical faculty: results of an ongoing multi-center survey. Plos one. 2011;6(10):1-10

[6] Minister of Administrative Reform Regulation of Indonesia. No : PER/17/M.PAN/9/2008. Functional position of clinical educator doctor and credit score.

[7] LamPT-Kes ORL-HNS's spesialist medical education program Faculty of Medicine Diponegoro University-Kariadi Hospital accreditation data in 2017, [Unpublished data].

[8] Sugiyono AT. Memahami penelitian kualitatif : tehnik pengambilan sampel dan analisis data. Bandung: Alfabeta. 2013

[9] Creswell JW, Research design : Qualitative, quantitative, and mixed methods approaches 3rd ed. SAGE Publications. 2009 p173-194

[10] Schiekirka S, Feufel MA, Herrmann-Lingen C, Raupach T. Evaluation in medical education: A topical review of target parameters, data collection tools and confounding factors. Ger Med Sci. 2015;13:1-19

[11] Kim HB, Myung SJ, Yu HG, Chang JY, Shin CS. Influences of faculty evaluating system on educational performance of medical school faculty. Korean $\mathbf{J}$ Med Educ. 2016;28(3):289-94

[12] Fluit CR, Feskens R, Bolhuis S, Grol R, Wensing M, Laan R. Repeated evaluations of the quality of clinical teaching by residents. Perspect Med Educ. 2013;2:87-94

[13] Fluit C, Bolhuis S, Grol R, Ham M, Feskens R, Laan R, et al. Evaluation and feedback for effective clinical teaching in postgraduate medical education: validation of an assessment instrument incorporating the CanMEDS roles. Med Teach. 2012;34(11):893-901

[14] Yeo S. Course quality management based on monitoring by students at a medical school. Korean J Med Educ. 2018;30(2):141-152 